\title{
Antibiotics in the Community During the COVID-19 Pandemic: A Qualitative Study to Understand Users' Perspectives of Antibiotic Seeking and Consumption Behaviors in Bangladesh
}

\author{
Md Abul Kalam (D)', Shahanaj Shano ${ }^{2,3}$, Sharmin Afrose ${ }^{4}$, Md Nasir Uddin ${ }^{2}$, Nafis Rahman ${ }^{5}$, \\ Faruk Ahmed Jalal (D) ${ }^{6}$, Samira Akter ${ }^{7}$, Ariful Islam ${ }^{3,8}$, Md Mujibul Anam (iD) ${ }^{7}$, \\ Mohammad Mahmudul Hassan (1D ${ }^{9}$
}

'Bangladesh Country Office, Helen Keller International, Dhaka, I2I2, Bangladesh; ${ }^{2}$ Institute of Epidemiology, Disease Control and Research (IEDCR), Dhaka, 12I2, Bangladesh; ${ }^{3}$ EcoHealth Alliance, New York, NY, USA; ${ }^{4}$ World Food Programme, Dhaka, I207, Bangladesh; ${ }^{5}$ Department of Public Health, American International University of Bangladesh, Dhaka, 12/2, Bangladesh; ${ }^{6}$ Handicap International - Humanity \& Inclusion, Dhaka, 1212 , Bangladesh; ${ }^{7}$ Department of Anthropology, Jahangirnagar University, Savar, Dhaka, 1243, Bangladesh; ${ }^{8}$ Centre for Integrative Ecology, School of Life and Environmental Science, Deakin University, Geelong Campus, Warrnambool, VIC, 3216, Australia; ${ }^{9}$ Chattogram Veterinary and Animal Science University, Chattogram, 4225, Bangladesh

Correspondence: Md Abul Kalam, Helen Keller International, Bangladesh Country Office, Dhaka, 12/5, Bangladesh, Tel $+8801912408 / 48$, Email a.kalam724@gmail.com

Introduction: The COVID-19 pandemic is thought to have led to increased "inappropriate" or "unjustified" seeking and consumption of antibiotics by individuals in the community. However, little reference has been made to antibiotic seeking and using behaviors from the perspectives of users in Bangladesh during this health crisis.

Purpose: This study seeks to document how antibiotic medicines are sought and used during a complex health crisis, and, within different contexts, what are the nuanced reasons why patients may utilize these medicines sub-optimally.

Methods: We used an exploratory, qualitative design. Forty semi-structured telephone interviews were conducted with people diagnosed with COVID-19 ( $\mathrm{n}=20$ ), who had symptoms suggestive of COVID-19 ( $\mathrm{n}=20)$, and who had received care at home in two cities between May and June 2021 in Bangladesh. In this study, an inductive thematic analysis was performed.

Results: The analysis highlighted the interlinked relationships of antibiotic seeking and consumption behaviors with the diversity of information disseminated during a health crisis. Antibiotic-seeking behaviors are related to previous experience of use, perceived severity of illness, perceived vulnerability, risk of infection, management of an "unknown" illness and anxiety, distrust of expert advice, and intrinsic agency on antimicrobial resistance (AMR). Suboptimal adherence, such as modifying treatment regimes and using medication prescribed for others, were found to be part of care strategies used when proven therapeutics were unavailable to treat COVID-19. Early cessation of therapy was found to be a rational practice to avoid side effects and unknown risks.

Conclusion: Based on the results, we highly recommend the take up of a pandemic specific antimicrobial stewardship (AMS) program in the community. To deliver better outcomes of AMS, incorporating users' perspectives could be a critical strategy. Therefore, a co-produced AMS intervention that is appropriate for a specific cultural context is an essential requirement to reduce the overuse of antibiotics during the COVID-19 pandemic and beyond.

Keywords: COVID-19, antimicrobial resistance, consumption behavior, antimicrobial stewardships, community engagement, Bangladesh

\section{Introduction}

The current pandemic caused by Severe Acute Respiratory Syndrome Coronavirus 2 (SARS-CoV-2) or COVID-19 poses an immense threat to global public health. Since 15th October 2021, COVID-19 has infected almost 240 million people 
resulting in over 4.8 million deaths globally. ${ }^{1}$ Patients can develop severe complications associated with bacterial pathogens, ${ }^{2}$ which might be responsible for even higher mortality rates. ${ }^{3,4}$ Antimicrobial therapy is important for managing confirmed COVID-19 cases with associated bacterial or fungal infections. ${ }^{5}$ However, the increased use of antibiotics and antifungals is somewhat counterproductive in the global effort to reduce antimicrobial resistance. ${ }^{6}$ A systematic review reported that increased use of antimicrobials while treating COVID-19 patients in Asia, Europe, and other regions ${ }^{7}$ is augmenting the threat of antimicrobial resistance (AMR) globally. ${ }^{8}$ Lower- and Middle-income Countries (LMICs) (like Bangladesh) are prone to the twin burdens of increased risk from COVID-19 and AMR due to poorly resourced health programs, health care services and health governance, and ineffective regulatory and legislative mechanisms to control antibiotic use. ${ }^{9-12}$ As countries have started administering vaccines and therapeutics, which are tackling the problems of the COVID-19 pandemic, the global threat of AMR remains unchecked. ${ }^{7}$ In LMICs, infection and fatality rates are higher, and mass vaccination has been challenged. ${ }^{13}$ The situation is even worse in lower resource settings, like Bangladesh, where mass vaccination is a major concern due to the unequal distribution of the vaccine ${ }^{14}$ and vaccine hesitancy. ${ }^{15}$ AMR specialists have warned that misuse or overuse of antibiotics during the COVID-19 pandemic can vary, including seeking antibiotics without clinical confirmation of co-infection, ${ }^{8,16}$ suboptimal adherence, ${ }^{17,18}$ and self-medication ${ }^{19,20}$.

At the user level, "unjustified" or "irrational" behaviors are thought to result in failing to start a course of therapy, omission of doses, early cessation of therapy, errors in dose quantity, "inappropriate" intervals between doses, modifications to the regimes, and the use of shared prescriptions and medicines. ${ }^{21-24}$ Self-medicating with antibiotics is framed as another "problematic" behavior. ${ }^{25,26}$ However, these framings are not sufficient to explain the underlying causes of people's behavior and their attitudes toward antibiotic seeking and consumption. ${ }^{27}$ Within the social sciences, these framings are described as one-dimensional and there is a need to explore patients' beliefs and wider life-worlds. ${ }^{28}$ Scholars such as Conrad, ${ }^{29}$ Geest, Whyte and Hardon, ${ }^{30}$ Hardon and Sanabria, ${ }^{31}$ and Cohen ${ }^{32}$ have argued that these "doctor centric" or "biological" framings fail to understand the use of medicine and recommend the study of noncompliance from the patients' perspective. From a social perspective, the use of medicines is relational and interlinked with the diverse inscriptions and is part of an ongoing, constantly evolving interaction between the patients and medicines themselves. ${ }^{33}$ Subsequently, the meanings of infections and how people adopt their own practices based on a complex set of beliefs about the body, health threats, and medical treatment are also critical factors to examine. ${ }^{34-36}$ Studying the emic or users' perspective of risk and illness, and professional identity and power plays a significant role in determining the nuanced reasons for suboptimal consumption and "inappropriate" behaviors and attitudes. ${ }^{35,37}$

Studying the context, culture, and behaviors is critical to engaging the community in an antimicrobial stewardship program (AMS), thereby controlling the global spread of disease and the emergence of AMR. ${ }^{38}$ As the consumers of antibiotics, individual community members can contribute to the control of AMR by limiting antibiotic use to where there is a clear benefit. ${ }^{38-40}$ While promoting appropriate and safe use of antibiotics, increased community engagement through community dialogue is considered to be a promising approach for tackling AMR. ${ }^{41}$ Before designing an effective AMS in the community, exploring people's diverse behaviors, thoughts, and the cultural context is highly recommended, particularly while investigating antibiotic seeking, suboptimal use, and medication adherence ${ }^{41-43}$ However, there is little insight into why and in what context people seek antibiotic medicines, and how they use these medicines in Bangladesh during this pandemic. Previous studies in the pre-pandemic era explained the non-compliance and selfmedication with antibiotics using demographic factors, ${ }^{44}$ which often fail to understand from a cultural context the relationships and interlinkages between antibiotic seeking decisions and consumption behaviors, and the diversity of information available. ${ }^{33}$ Considering antibiotic use as a "socially embedded phenomenon", ${ }^{32}$ this paper sheds light on how patients' antibiotic medicine seeking and use decisions are made within a complex loop of relationships, situations, roles, and identities that are based on the social and cultural contexts in addition to their therapeutic function. Taking into account the social and cultural meanings of antibiotics that impact on the quality of provision and use, ${ }^{45}$ the paper also focuses on patients' agency concerning the non-medical effects of antibiotics. The findings will inform public health policy and communications about the pandemic and its intersections with AMS in the community in Bangladesh through community engagement. 


\section{Methods and Materials \\ Study Design}

As a qualitative approach is the preferred paradigm in the study of socio-cultural aspects of seeking medicine or adhering to their instructions for use, ${ }^{46}$ the study employed an exploratory, qualitative design. Due to social distancing and other restrictions put in place to control the spread of the virus, the interviews were conducted over the telephone. Where applicable, the study followed COREQ guidelines of reporting qualitative studies. ${ }^{47}$

\section{Study Settings}

The study was carried out in two major cities, Dhaka and Chattogram, both epicenters in terms of the infection and fatality rates in Bangladesh at the time of data collection (May to June 2020). ${ }^{48}$ Bangladesh reported its first COVID-19 case on 8 March 2020. The country was facing severe challenges in managing confirmed cases in hospital settings due to a poorly resourced health structure and human resource issues, especially during the period in which infection and mortality rates were climbing. ${ }^{49}$ Apart from the health system response, the government enacted a guideline for treating patients with mild symptoms and asymptomatic cases in the home setting. ${ }^{50}$ Despite various guidelines and treatment protocols, surveys showed the increased use of antibiotics during the pandemic in the community. ${ }^{51,52}$ A qualitative study reported a number of socio-cultural and structural drivers of antibiotic use during this time. ${ }^{53}$ Earlier studies reported easy access to antibiotic medicines through over the counter (OTC) sales that did not require a prescription to be shown. ${ }^{26}$ Along with professional doctors, unqualified providers in the informal sector also prescribe antibiotics. ${ }^{54}$ The aggressive and unethical marketing practices of pharmaceutical companies are also linked with the over-prescription of antibiotics ${ }^{55}$ consequently, most antimicrobials are prescribed based on a best-guess. ${ }^{56}$ Considering the twin burdens of COVID-19 and antibiotic use, these two urban sites were selected to understand people's antibiotic seeking and consumption behaviors from a socio-cultural perspective in the context of COVID-19.

\section{Sampling and Recruitment Procedure}

Purposive sampling was used to recruit participants through social media (Facebook) posts and network sampling to achieve saturation. Potential participants were invited for interview if they met the following criteria: i) having clinically tested positive for COVID-19; ii) having had symptoms suggestive of COVID-19 (such as fever, dry cough, sore throat, and loss of taste or smell); iii) having received home care; and iv) having consumed antibiotics. These criteria were based on the World Health Organization (WHO) interim guidelines, which state that antibiotics can be used where there is confirmed co-infection among patients with COVID-19, but that their use is discouraged for those with mild symptoms who receive home care. $^{57}$

At the design stage, we envisioned that seeking and consumption behaviors would vary according to clinically confirmed cases and symptoms, age, social location, and the level of education. Capturing such variation is important since it is likely that different generations have varying attitudes and experiences of antibiotics. After completing 28 interviews and i) listening to the audio recordings, ii) careful reading of the transcripts, iii) inductive coding, and iv) identification of the broad areas of initial themes, we decided that there was insufficient data from individuals having COVID-19 with symptoms. We then recruited another 12 participants based only on their gender, level of education, and age. At this point, we found no emerging themes or categories in their seeking and using behaviors. Finally, 40 semistructured telephone interviews were conducted with people who had COVID-19 ( $\mathrm{n}=20)$ and suggestive symptoms $(\mathrm{n}=20)$.

The researchers (MAK, MMH, SS and AI) had an initial discussion with potential participants (who showed an interest in taking part in the study) to provide an overview of the study and to obtain their informed consent, and give them the interview schedule. In doing so, the team and the participants had a series of discussions over the phone. These interactions allowed the research team to build rapport and gain trust with the research participants. Two research assistants (RAs), MNU (male) and SA (female), then interviewed them over the phone. Several calls were needed with some participants to complete the interviews and follow-up discussions. 


\section{Interview Guide}

A semi-structured interview guideline was developed based on an extensive literature review. This guide included preliminary questions regarding participants' health status, history of chronic disease and COVID-19 infection, health-seeking behavior, antibiotic-seeking attitudes, and consumption behavior (please see supplementary file). The primary version of the interview guide was reviewed by a group of experts in the subject area. Before conducting the interviews, the guide was piloted with four participants in order to check its validity and linguistic suitability, to determine probing and additional questions, and the comprehensibility of the RAs. The pilot interviews were not included in the current analysis.

\section{Ethical Approval and Data Collection}

The study was conducted in accordance with human subject research in the Declaration of Helsinki 1964 and its later amendments. Ethical approval was obtained from Chattogram Veterinary and Animal Sciences University, Chattogram, Bangladesh (CVASU) Research Ethics Committee [approval number CVASU/Dir (R\&E)/EC/2020/169(3)]. As the study was conducted during strict restrictions to contain the spread of COVID-19, the interviews were conducted by telephone. Hence, we obtained verbal consent from the participants with the approval of the ethics committee. The participants consented to the publication of the work after the anonymization of their names and use of pseudonyms. Consent was recorded in a digitized audio recorder before starting the interviews. The audio-recorded interviews were conducted between May to June 2020, each lasting between 40 and 90 minutes.

\section{Data Analysis}

The analysis method was based on an inductive, grounded theory approach from a constructivist perspective as described in Constructing Grounded Theory: A Practical Guide Through Qualitative Analysis by Kathy Charmaz. ${ }^{58}$ The data analysis process was followed by i) listening to the audio recordings, ii) careful reading of the transcripts, iii) inductive coding, iv) identifying the themes, v) reviewing the themes, and vi) writing up the findings. The interview recordings were initially transcribed verbatim in Bengali before being translated into English by MNU, SA and FAJ. MAK, SS, SA and MNU checked all transcripts against the audio recordings and translated versions of the transcripts for accuracy and completeness. In doing so, they first listened to the audio recordings to match the written text, then read the English versions to check them against the Bengali transcripts.

Two authors (MAK and SS) coded the same four interview transcripts to generate, by consensus, a preliminary set of open codes derived from the texts. These codes were then used by MMH, MNU and SA to double code a further four interviews. During this phase, a constant comparison was made within and between interview transcripts and between the codes that were developed by MAK and SS for deep-dive analysis. These primary codes were then used to guide the rest of the transcripts, with additional inductive codes added whenever new insights emerged. These codes were then organized into themes and sub-themes. In order to determine the initial codes that made the most analytic sense to categorize all the data incisively and completely, we then performed a focused or selective coding exercise. An axial coding technique was used to bring data back together again to build coherence between categories and sub-categories. Transcripts were first anonymized and a pseudonym inserted for each interview transcript before finally importing them into MAXQDA Standard (2020, VERBI Software, Berlin, Germany) for coding and analysis.

\section{Results}

\section{Background Information About the Participants}

Table 1 represents the research participants' details. An equal number of interviews were conducted with women and men ( $\mathrm{n}=20$ each). The majority of them did not have chronic conditions, and most of the participants belonged to the $24-$ 40 years of age category $(n=31)$. The majority of the participants had completed a university degree. Most of them were involved with different services at both public and private agencies. Before the pandemic, many participants had taken antibiotics in the last year for a range of reasons. 
Table I Details of the Participants

\begin{tabular}{|c|c|c|}
\hline \multicolumn{2}{|l|}{ Characteristics of the Participants } & \multirow{2}{*}{$\begin{array}{l}\text { Number (\%) } \\
20(50)\end{array}$} \\
\hline Type of participant & People with COVID-19 & \\
\hline & People with suggestive symptoms & $20(50)$ \\
\hline \multirow[t]{2}{*}{ Gender } & Male & $20(50)$ \\
\hline & Female & $20(50)$ \\
\hline \multirow[t]{3}{*}{ Age } & $24-30$ & $15(37.5)$ \\
\hline & $31-40$ & $16(40)$ \\
\hline & $4 I-50$ & $9(22.5)$ \\
\hline \multirow[t]{4}{*}{ Education } & $\mathrm{MA} / \mathrm{MSc} / \mathrm{MSS}$ & $19(47.5)$ \\
\hline & $\mathrm{BA} / \mathrm{BSc} / \mathrm{BSS}$ & $14(35)$ \\
\hline & 12th grade & $3(7.5)$ \\
\hline & 10th grade & $4(10)$ \\
\hline \multirow[t]{5}{*}{ Occupation } & Service & $17(42.5)$ \\
\hline & Home maker & II (27.5) \\
\hline & Student & $5(12.5)$ \\
\hline & Business & $5(12.5)$ \\
\hline & Others & $2(5)$ \\
\hline \multirow[t]{4}{*}{ History of chronic disease } & No chronic disease & $32(80)$ \\
\hline & Asthma & $4(10)$ \\
\hline & Diabetes & $3(7.5)$ \\
\hline & Cancer & $\mathrm{I}(2.5)$ \\
\hline \multirow[t]{3}{*}{ Number of times antibiotics taken in the last year } & Not taken & $19(47.5)$ \\
\hline & Yes & $18(45)$ \\
\hline & Could not recall & $3(7.5)$ \\
\hline
\end{tabular}

\section{Thematic Findings}

All the participants consumed antibiotics for COVID-19 and suggestive symptoms. At the recruitment interviews, potential participants were asked to name the brands of these antibiotics. Analysis of the brand names (were anonymized from the transcripts) revealed that the participants consumed a number of antibiotic groups including azithromycin, doxycycline, amoxicillin-clavulanic acid, erythromycin, ceftriaxone, and ciprofloxacin. Before presenting the thematic results on antibiotic seeking and consumption behaviors, insights into the meanings of antibiotics are described below to help contextualize the explanations of seeking and consumption behaviors.

Along with the pharmaceutical properties of these medicines, the analysis found diverse perceptions and understandings that are related to the socio-cultural properties of these medicines. A number of research participants, including those who had COVID-19 and those who had COVID-19-like symptoms, explained that antibiotics are powerful medicines that accelerate fast recovery and counter almost all diseases. In terms of using antibiotics, it was found that these medicines could kill all viruses and bacterial pathogens. Some participants also indicated that these medicines could 
prevent bacterial and viral infections, and work as immunity boosters. Some also stated that these medicines are used to reduce fever, sore throat, stomach ache and serious injury, and to treat diarrhea, coughs, and skin and urinary infections. Many of them had used antibiotics in previous episodes of similar illness.

A summary of the thematic findings on participants' antibiotic seeking and consumption behaviors is provided in Table 2. These themes emerged from the responses provided by the participants and accord with the temporal and risk management aspects of antibiotic seeking and use.

\section{Antibiotics Seeking Behaviors}

The analysis revealed five themes related to seeking antibiotics: 1) when a prompt decision is made to seek antibiotics; 2) when home remedies and "normal" medicines fail to cure the symptoms (wait and see); 3) when the symptoms become severe; 4) when close contacts (such as family members) test positive for COVID-19; and 5) hesitation, dilemma and self-negotiation during antibiotic seeking decision making. The responses were the results of complex reasoning processes, an acute awareness of the circumstances in which they found themselves, and knowledge of COVID-19 and its symptomatic treatments.

\section{Seeking Antibiotics as Soon as Testing Positive or Seeing Symptoms}

The participants who had tested positive for COVID-19 reported that they needed to seek antibiotics as soon as the infection was confirmed. They preferred to consume antibiotics so that their condition remained under "control". For example, Sourav (47 years, tested positive) explained:

... ...... As many things were unknown, I did not want to take risk. I thought my symptoms could be reduced if I start antibiotics. [Later] ... I knew it because I took it previously when I was suffered from a high fever and body ache. So, I started antibiotics from the very first day when I got the test report.

Previous experiences of speedy recovery from the (COVID-19-like) symptoms encouraged this participant to seek antibiotics. Other participants also gave similar narratives. They did not want to take the risk of further complications due to having the virus. Anowara (42 years, tested positive) explained:

I was very anxious about my condition. I started the antibiotic on that day [the day report was delivered]. I have a previous history of asthma and had to take antibiotics at other times. And I know asthma patients are more vulnerable to the virus. I did not want to take time to start antibiotics.

They focused on reducing the potential damage as a result of getting the virus. While most of the participants immediately sought antibiotics to treat the infection, their seeking approach was perceived as an "appropriate" step based on previous consumption practices and their perceived vulnerabilities due to their medical history.

However, those who tested positive and sought antibiotics immediately offered other reasons that were closely related to COVID-19 induced anxiety and the unpredictable development of their illness. Kamran (38, tested positive) explained:

I was very nervous, and my blood pressure was increased to see my test report. I did not understand what to do. I know antibiotics help to cure these symptoms, and then I started XXX (brand name of azithromycin) from the very first day.

At the time of the interviews, the severity of COVID-19 in terms of increased infection and fatality rates may have been responsible for the anxiety felt by many of the participants. Seeking antibiotics immediately was related to risk and anxiety management.

\section{Seeking Antibiotics When Home Remedies and "Normal Medicine" Proved to be Ineffective}

Participants tried several home remedies including warm water vapor, masala tea, green tea, black seed, honey, lemon with warm water, turmeric (Curcuma longa), tulsi (Ocimum tenuiflorum) syrup, and black tea. Traditionally, these home remedies are popular for treating symptoms suggestive of COVID-19. Individuals with symptoms and mild cases of COVID-19 sought antibiotics when home remedies failed to cure these symptoms. Raihan (34, with symptoms) explained: 
Table 2 Summary of Thematic Findings

\begin{tabular}{|c|c|c|c|c|}
\hline Themes & Sub-Theme & Explanations & $\begin{array}{l}\text { Number of } \\
\text { Participants }\end{array}$ & $\begin{array}{l}\text { Nature of } \\
\text { Participants }\end{array}$ \\
\hline \multirow[t]{5}{*}{$\begin{array}{l}\text { Antibiotic } \\
\text { seeking } \\
\text { behavior }\end{array}$} & $\begin{array}{l}\text { As soon as tested positive or } \\
\text { having symptoms. }\end{array}$ & $\begin{array}{l}\text { Those who had tested positive with COVID-19 and } \\
\text { had severe symptoms sought antibiotics to keep the } \\
\text { health condition under "control" from further } \\
\text { damage and manage anxiety. }\end{array}$ & 16 & $\begin{array}{l}\text { Individuals with } \\
\text { COVID- } 19=11 \\
\text { Individuals with } \\
\text { symptoms }=5 \\
\text { Gender: } M a n=9 ; \\
\text { Woman=7 } \\
\text { Age group: }<40=6 \text {; } \\
>40=10 \\
\text { Chronic illness=8; } \\
\text { Education: Up to } \\
\text { BA/BSc=10; } M A / \\
M S c=6\end{array}$ \\
\hline & $\begin{array}{l}\text { Seeking antibiotics when home } \\
\text { remedies and "normal" } \\
\text { medicines fail to cure the } \\
\text { symptoms. }\end{array}$ & $\begin{array}{l}\text { Due to the perceived side-effects of antibiotics, } \\
\text { home remedies and normal medicines were used, } \\
\text { and the body observed in the first place. Sought } \\
\text { antibiotics when ailment was deteriorating. }\end{array}$ & 13 & $\begin{array}{l}\text { Individuals with } \\
\text { COVID-19=3 } \\
\text { Individuals with } \\
\text { symptoms=10 } \\
\text { Gender: } M a n=5 \text {; } \\
\text { Woman=8 } \\
\text { Age group: }<40=4 \text {; } \\
>40=9 \\
\text { Education: Up to } \\
\text { BA/BSc=7; MA } \\
\text { MSc=6 }\end{array}$ \\
\hline & When the symptoms get severe. & $\begin{array}{l}\text { Sought antibiotics in the case of critical signs and } \\
\text { symptoms of COVID-19 such as shortness of } \\
\text { breathing, chest pain, and lower oxygen level, } \\
\text { indicating secondary co-infection. }\end{array}$ & 7 & $\begin{array}{l}\text { Individuals with } \\
\text { COVID-19=6 } \\
\text { Individuals with } \\
\text { symptoms=1 } \\
\text { Gender: } \text { Man=7 } \\
\text { Age group: }<40=1 \text {; } \\
>40=6 \\
\text { Education: Up to } \\
\text { BA/BSc=4; } M A / \\
M S c=3\end{array}$ \\
\hline & $\begin{array}{l}\text { Close contacts tested positive } \\
\text { with COVID-19. }\end{array}$ & $\begin{array}{l}\text { Risk of spreading the virus influenced close } \\
\text { contacts, such as other family members, to seek } \\
\text { antibiotics. }\end{array}$ & 4 & $\begin{array}{l}\text { Individuals with } \\
\text { symptoms=4 } \\
\text { Gender: } M a n=1 ; \\
\text { Woman=3 } \\
\text { Age group: }<40=4 ; \\
\text { Education: Up to } \\
\text { BA/BSc=4 }\end{array}$ \\
\hline & $\begin{array}{l}\text { Hesitation, dilemma, and self- } \\
\text { negotiation. }\end{array}$ & $\begin{array}{l}\text { The concern about AMR and confusion around the } \\
\text { effectiveness and appropriateness of antibiotic use } \\
\text { in treating a viral disease led to a dilemma. }\end{array}$ & 4 & $\begin{array}{l}\text { Individuals with } \\
\text { COVID-19 =4 } \\
\text { Gender: } \text { Man=I, } \\
\text { Woman=3 } \\
\text { Age group: }<40=4 \text {; } \\
\text { Education: } M A \text { / } \\
\text { MSc=4 }\end{array}$ \\
\hline
\end{tabular}

(Continued) 
Table 2 (Continued).

\begin{tabular}{|c|c|c|c|c|}
\hline Themes & Sub-Theme & Explanations & $\begin{array}{l}\text { Number of } \\
\text { Participants }\end{array}$ & $\begin{array}{l}\text { Nature of } \\
\text { Participants }\end{array}$ \\
\hline \multirow[t]{4}{*}{$\begin{array}{l}\text { Antibiotics } \\
\text { consumption } \\
\text { behavior }\end{array}$} & Following prescribed doses. & Trusted the physician's prescription and regimes. & 13 & $\begin{array}{l}\text { Individuals with } \\
\text { COVID-I=II } \\
\text { Individuals with } \\
\text { symptoms=2 } \\
\text { Gender: Man=7; } \\
\text { Woman=6 } \\
\text { Age group: }<40=2 \text {; } \\
>40=1 \text { I } \\
\text { Chronic illness=8 } \\
\text { Education: Up to } \\
\text { BA/BSc=9; MA/ } \\
\text { MSc=4 }\end{array}$ \\
\hline & $\begin{array}{l}\text { Following regimes for antibiotic } \\
\text { use of others. }\end{array}$ & $\begin{array}{l}\text { Recovered patient's prescription is tested and it is } \\
\text { believed that following that prescription and } \\
\text { regimes would help to cure the disease and } \\
\text { symptoms. }\end{array}$ & 12 & $\begin{array}{l}\text { Individuals with } \\
\text { COVID-19=2 } \\
\text { Individuals with } \\
\text { symptoms=10 } \\
\text { Gender: Man=10; } \\
\text { Woman=2 } \\
\text { Age group: }<40=9 \text {; } \\
>40=3 \\
\text { Education: Up to } \\
\text { BA/BSc=8; MA/ } \\
\text { MSc=4 }\end{array}$ \\
\hline & $\begin{array}{l}\text { Stopped taking when felt better } \\
\text { or on experiencing side-effects. }\end{array}$ & $\begin{array}{l}\text { Stopped taking due to side effects that would cause } \\
\text { further damage or when symptoms disappeared. }\end{array}$ & 10 & $\begin{array}{l}\text { Individuals with } \\
\text { COVID- } 19=4 \\
\text { Individuals with } \\
\text { symptoms=6 } \\
\text { Gender: } \text { Man=7; } \\
\text { Woman=3 } \\
\text { Age group: }<40=8 \text {; } \\
>40=2 \\
\text { Chronic illness=2 } \\
\text { Education: Up to } \\
\text { BA/BSc=6; MA/ } \\
\text { MSc }=4\end{array}$ \\
\hline & $\begin{array}{l}\text { Multiple suggestions, multiple } \\
\text { regimens, and multiple } \\
\text { antibiotics. }\end{array}$ & $\begin{array}{l}\text { Sought treatments from multiple physicians when } \\
\text { the conditions did not improve. }\end{array}$ & 5 & $\begin{array}{l}\text { Individuals with } \\
\text { COVID-19 =3 } \\
\text { Individuals with } \\
\text { symptoms=2 } \\
\text { Gender: Man=2; } \\
\text { Woman=3 } \\
\text { Age group: }<40=5 \text {; } \\
\text { Education: Up to } \\
\text { BA/BSc=3; MA/ } \\
\text { MSc=2 }\end{array}$ \\
\hline
\end{tabular}


Usually, I suffer from cold and throat-ache like all the year-round. At that time, I used to take tulsi leaves, ginger, and honey. I started taking these for my symptoms. But this time [indicating COVID-19 like symptoms], these remedies did not work. I tried for five days, but I was not cured. Then I decided to start antibiotics.

Several participants preferred traditional cures to avoid the side effects of biomedicine. Interestingly, the people who consumed antibiotics in the later stages of infection also reported the failure of traditional home remedies and consequently took antibiotics. For example, Nasima (28, with symptoms) shared her concern over the side effects of antibiotics:

I hate taking tablets. They are artificially made with chemicals, which have side effects. When I felt throat itching and cold, I started taking warm water, black tea with ginger, and masala. But these were not working. I started antibiotics as I know antibiotics help to cure throat ache and cold.

Many other participants who reported perceived side effects of biomedicines and therefore, tried home remedies instead, explained that taking antibiotics was related to a sense of security, risk avoidance, and self-health management, which justified their use.

A number of other participants reported consuming antibiotics when "normal" medicines failed to cure the symptoms. The "normal" medicines were defined as those which were readily available, were self-administered with doses unspecified by specialists, and which could be used as first aid measures. Participants took antibiotics when they realized that these medicines did not cure the symptoms. For example, Rana (29, with symptoms) said:

I took XXX [brand name of paracetamol] and XXX [brand name of Montelukast Sodium] thrice a day for three days. Then I realized there are no improvement of my symptoms. Then I started taking antibiotics for five days after consulting with a doctor.

Such attitudes serve to justify the "appropriateness" of antimicrobial therapy when normal medicines fail to cure the symptoms. A common perception among participants was that physicians usually suggest these normal medicines first, before prescribing an antibiotic when they fail to cure the symptoms.

\section{Seeking Antibiotics Based on the Perceived Severity of the Symptoms}

A cluster of narratives on participants' antibiotic seeking behavior was related to the perceived severity of COVID-19 symptoms. In particular, they sought antibiotics when they observed the critical signs of COVID-19 such as shortness of breathing, chest pain, and lower oxygen levels. These signs are indicative of a secondary infection. Yunus (49, with COVID-19) demonstrates this concern:

I heard about secondary infection. I was unsure whether I had that [secondary infection] on my lungs. I was suffering from chest pain. I consulted with a doctor who prescribed antibiotics. Then I started antibiotics doses.

Because the participants received care in the home setting, they were unsure about whether they had secondary infections. However, shortness of breath was another important symptom prompting some participants to seek antibiotics. Rehena (45, with COVID-19) explained:

The symptoms were like stuck on my body, no change, nothing. I was monitoring my breathing counts every time. On the fifth day, I could not be able to take a long breath. Then I decided that I should not wait anymore and bought antibiotic doses for seven days.

The degree of suffering felt due to the perceived severity of illness influenced participants' antibiotic seeking attitudes. Several other participants had sought antibiotics where they had severe sore throat, and the loss of smell and taste.

\section{Seeking Antibiotics When Close Contacts Tested Positive for COVID-19}

A few of the participants who had symptoms suggestive of COVID-19, reported taking antibiotics because close contacts (such as family member) had tested positive. The explanations indicated that antibiotics would have kept them safe from any perceived harm. Zahid (28, with symptoms) noted: 
I took care of my father from the very beginning after showing the symptoms. Initially I was unsure if he had the virus. Then we went for the test and got confirmation. He was tested positive for COVID-19. In the meantime, I stayed with him for taking care. I also had mild symptoms like fever and cold. I thought I should also take antibiotics to remain healthy.

The risk of spreading the virus influenced the attitudes of close contacts of those testing positive for COVID-19, such as family members, as antibiotics were perceived to be powerful enough to prevent them from having the virus and its associated harm.

\section{Hesitation, Dilemma, and Self-Negotiation}

A number of participants showed hesitancy and dilemma over whether antibiotics would be appropriate to seek in the case of a viral disease. Intrinsic agency was found among individuals who were hesitant about the nature of diseases and the type of medication to treat them. For example, Morshed (29) explains:

I was unsure if antibiotics [would] work against a viral disease. When my doctor suggested me, I got confused and did not take it. I googled to know how antibiotics might work. From the WHO [World Health Organization] report, I learned that the virus might attack the respiratory tract that could cause pneumonia, and antibiotics should be taken then.

This narrative shows how an individual's awareness of the action efficacy of antibiotics creates mistrust even when a professional suggests they take antibiotics. Their personal uncertainty about seeking antibiotics, their apprehension about the consequences of these decisions, and the sense of responsibility to their own body maintained this dilemma. Although the number of such participants was small, their explanations revolved around notions of "intolerance", "antibiotics may not work against any disease", and the "resistant body". For example, Rashida (30), a woman with COVID-19, explains:

The doctor suggested me to take XXX [brand name of antibiotics]. I was unsure whether I should take it or not; because I know about AMR by my work [She is a public health researcher]. I did not take it then ... .... because I thought taking antibiotics is unnecessary and it can cause resistance. I consulted with two other doctors to check if I need antibiotics. They also suggested it, but I did not take. Then I was feeling chest pain and breathing complication. Then I made contact with another doctor who provides care to COVID-19 patients. That doctor explained to me the need for antibiotics to treat secondary co-infection. I started antibiotics then.

This extract from Rashida presents the orthodox thinking about the misuse of antibiotics that increases resistance to them. For the same reason, she thought the doctor might have suggested antibiotics "unnecessarily". Interestingly, she cross-checked with other physicians before deciding to start the course. Whilst she had a good understanding of resistant bacteria, this was not the case for most participants. Those who had partial or accurate knowledge (on the action efficacy of antibiotics for viral disease) gained this from varied sources, including the media, family and friends, and medical practitioners.

\section{Antibiotic Consumption Behavior}

All participants reported consuming antibiotics by inclusion criteria and were generally confident in their efficacy to treat COVID-19 and its symptoms. Analysis revealed four sub-themes that are presented below.

\section{Following Prescribed Doses}

Individuals of advanced age who had COVID-19 were more likely to seek a prescription for antibiotics from a professional physician and were careful to adhere to the doctor's instructions on antibiotic regimes. For example, Foyez (49, with COVID) explained more about following the doctor's prescription:

Who else determines the doses and nature, except doctors? ... I do not know which antibiotics would be effective. Even I cannot tell you the generation of antibiotics available in the market. So, following the doctor's recommendation is safe.

This explanation presents the "good patient" characteristics of antibiotic adherence. Following doctors' suggestions was found "essential" to ensuring the effectiveness of antibiotics for a new disease like COVID-19. Zakir (46, with COVID19) explained: 
People were telling us to have antibiotics. They were not doctors. We, the Bengalis, prefer to buy medicine and consume it. This is not right, mainly when there is a new disease. People even do not know if antibiotics would work against a viral disease. So, I followed what my doctor suggested.

Added to this explanation, other narratives indicated a belief in expert knowledge and medical authority. However, this may not be followed appropriately by everyone in the general public. The following section presents some other perspectives.

\section{Following the Antibiotic Regimes of Others}

The study identified twelve participants (five tested positive and the other seven had suggestive symptoms) who followed the antibiotic regimes of other people. Some participants followed the prescription of a recovered patient; this was perceived to be effective because it had been "proven" to cure the symptoms. Karim (36, with COVID-19) explained this trust in a recovered patient's prescription:

I tried several normal medicines but my condition did not improve. I consulted with him [a recovered patient], and he shared his prescription. As he recovered, I thought the same antibiotics and dosage would be helpful to recover myself. [later] .... I was confident about doses and type as he recovered following the prescription.

Sharing the prescriptions of recovered patients was found to be common among family members where there was a COVID-19 patient who was prescribed antibiotics by a physician. Zahid (28, with symptoms) explained:

My father was tested positive. We consulted with a doctor and got the suggestion of antibiotics for 7 days. As I had symptoms, I also consumed antibiotics, the one that suggested for my father.

Why did you follow your father's prescription? For me, this is similar to follow a doctor's suggestion. The doctor would suggest me if I would have told him about my condition.

Several other participants with symptoms of COVID-19 used other peoples' prescriptions but modified the regimes as they had a mild case of the disease. In these cases, participants intentionally tried to reduce the number of antibiotics consumed. Nazrul (32, with symptoms) explained:

One of my acquaintances consulted with a doctor and took antibiotics. I took all the medicines that the doctors prescribed him. His doctor gave him 7 days course, but I took it for 5 days because my symptoms were not similar to him.

Prescription sharing through social media groups and digital platforms was found to be common within social networks. Participants sought suggestions from recovered patients, family members, and kin groups who had received prescriptions from doctors.

\section{Stop Taking Antibiotics When Feeling Better or Experiencing Side-Effects}

This study found ten participants who stopped using antibiotics when they felt better and their symptoms were cured. There are a range of explanations reported by the participants for stopping use or failing to complete the doses. For example, Rehena (33, with symptoms) explained:

When I found that my throat-ache was disappeared and my other symptoms gone, I decided to stop taking antibiotics. I thought consuming more doses would be worthless.

To stop taking antibiotics was a "rational" decision for Rehena as she recovered from the symptoms. Antibiotics were believed to have some side effects such as weakness, nausea, sleepiness, vomiting, and loss of hair, weight, and appetite. A few other participants stopped taking antibiotics when they observed these side effects. For example, Rokibul (28, with COVID-19) explained the reason for early cessation of antibiotics:

Doctors suggested me to have 5 days, but after taking three tablets, I felt unwell, having weakness and nausea. In the meantime, I could not eat well due to the virus. My condition became severe. So, I stopped taking. 
Early cessation was found to be a considered decision in order to prevent any side effects. Moreover, other participants were concerned about any "unknown" side effects if they were to take antibiotics to treat COVID-19.

\section{Multiple Suggestions, Multiple Regimens, and Multiple Antibiotics}

As there was some confusion among clinicians around treatment (at the time of the study), participants sought second opinions from multiple physicians when their conditions did not improve. Consequently, they changed the regime and type of antibiotics. Rahima (38, with COVID-19) explained:

My condition did not improve, then I consulted with a doctor, who suggested XXX [brand name] for 7 days. After 4 days, my symptoms remained similar. Then I decided to consult with another doctor. He prescribed me XXX [another brand name] and suggested me to take for 5 to 7 days.

Participants followed multiple regimes and used a range of brands, when considering their action efficacy to cure symptoms. Two participants followed multiple regimes and used different brands of antibiotics to find effective doses and brands that could help them to manage COVID-19-induced anxiety and to remain healthy.

\section{Discussion}

While recommendations have been made for taking part in the COVID-19 pandemic specific AMS program, ${ }^{7,10}$ there is little data to help design a culturally appropriate and inclusive AMS to reduce the overuse of antibiotics in the community. This qualitative study provides empirical evidence on users' perspectives on antibiotic seeking and consumption behaviors that can help design an inclusive AMS through community engagement. Diversified behaviors were captured taking into account participants' social location, age, educational attainment, and previous history of disease (Table 2). The diversity of antibiotic seeking behaviors showed: how the participants monitored their bodies for signs of infection, their previous experience of antibiotic consumption, and their attitudes towards a relatively new disease. Among our study population, antibiotics were perceived to be a powerful medicine that kills viruses and bacterial pathogens, being effective against all diseases and boosting immunity. The socio-cultural properties of antimicrobials might influence antibiotic seeking and consumption behaviors (Figure 1). These findings aligned with a recent study in which antibiotics are regarded as the "big boss", "final solution" and "preventive medicine". 53

The decision to seek antibiotics early depended both on participants' previous experience of managing similar illnesses and their level of COVID-19-induced anxiety (about spreading infection, the severity of the disease and death). In line with relevant international literature, ${ }^{59,60}$ participants with chronic infections were more likely to seek antibiotics immediately upon testing positive for COVID-19 as they considered themselves to be vulnerable. Consistent with an Australian study, ${ }^{60}$ several participants tended to "wait and see" before making the final decision to seek antibiotics. These attitudes provide insight into how participants viewed their health. Concerns were also raised about whether consuming biomedicine would make their condition worse due to the side effects. As a result, some relied on home remedies. However, in both cases, participants sought antibiotics in the later stages of the illness since these were considered to be the final solution. The relative explanations of such attitudes and behaviors confirmed the social embeddedness of antibiotic practices within society, ${ }^{28,32,61}$ particularly during a health crisis. ${ }^{36}$

Indeed, several participants were confused about whether they could have avoided using antibiotics in spite of their physicians' recommendations. This dilemma was due to either growing concern over AMR or the action efficacy of antibiotics to a viral infection. The intrinsic agency on the potential risk of this growing resistance and the perceived ineffectiveness of antibiotics against a viral disease highlighted concerns with how antibiotics might affect their bodies as described in the literature. ${ }^{62,63}$ Most importantly, participants' relative narratives show mistrust of physicians' suggestions in the context of a health crisis, which does not conform to the typical representation of "good patient" attitudes towards professional doctors. ${ }^{64}$ Self-negotiation and engagement with risks might have been influenced by the perceived severity of the illness and therefore, their trust in professional advice. ${ }^{65}$ This may have been due to the sudden health crisis being caused by a relatively "new disease" with no proven therapeutics by which to tackle it.

While exploring antibiotic consumption behavior, self-medication practice was found to be common (with some exceptions) among individuals who had been diagnosed with COVID-19. Elderly individuals with COVID-19 were more 


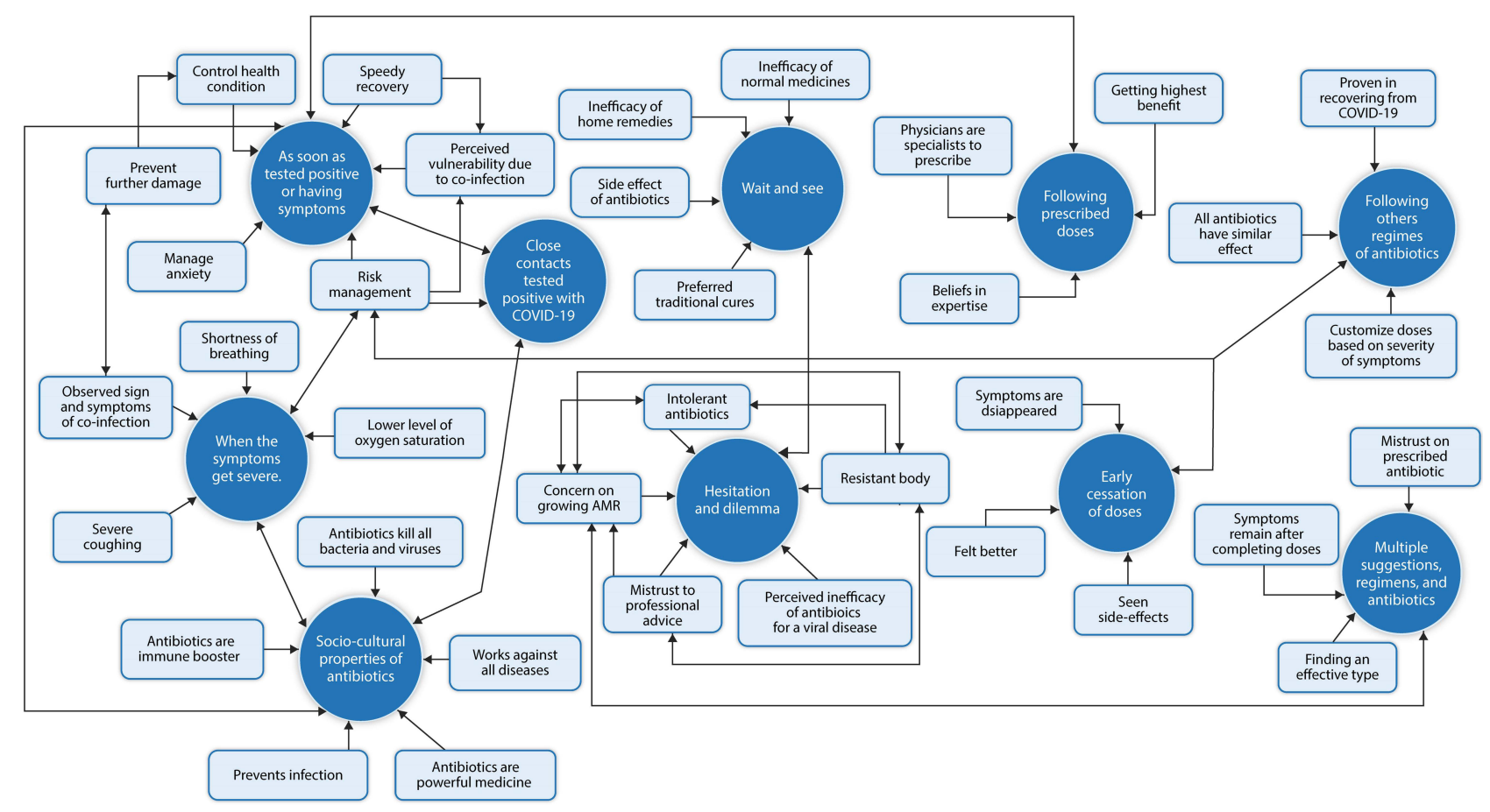

Figure I Significant matrix of socio-cultural aspects of antibiotics seeking and consumption behaviors: retrieved from inductive, grounded theory analysis.

likely to consult a physician and follow the prescribed treatment regimes. Trust in the expertise and skills of professionals to give appropriate instructions make age a more powerful mediator of behavior. ${ }^{60}$ While following physicians' suggestions and recommendations is positively associated with controlling AMR at the community level, ${ }^{66}$ in the case of COVID-19, antibiotics are viewed as necessary when the presence of a secondary co-infection is confirmed. ${ }^{7}$ In the current study, participants' self-medication behavior was purposeful and linked to their previous consumption experience. Self-medicating with antibiotics was thought to result in inappropriate dosing and duration of treatment, contributing to resistant strains of bacteria. ${ }^{7,67}$ However, self-medication was seen to be a strategy for self-care in this study. The international literature has described self-medication as an integral part of society's response to ill health. ${ }^{60,68}$ In this health crisis context, self-medicating with antibiotics might have been driven by socio-cultural factors, such as beliefs in the efficacy of antibiotics (the concept of "big medicine"), anxiety management (due to increased infection and mortality rates, and social stigma) and poor response from the health system in diagnosing and treating COVID-19. ${ }^{53}$ Moreover, Bangladesh has also faced severe challenges in terms of managing confirmed cases in hospital settings due to infrastructural and staffing issues. ${ }^{49}$ Evidence also suggested that premature hype surrounding possible therapies for COVID-19 was responsible for antibiotic overuse. ${ }^{8}$ These factors are partially responsible for the widespread use of antibiotics among home-based patients. ${ }^{51}$ To make AMS programs more effective, an understanding of these nuanced reasons for self-medication from the perspective of patients is needed. ${ }^{45,68}$

Modifications to the regimen were also reported by participants. This study found three types of modification, ie, shortening the regimen, stopping use when feeling better, and observing the side-effects. The narratives in this study indicated that these behaviors were relational rather than irrational, a view which is also evident in the social science literature. ${ }^{32}$ While other studies noted how taking antibiotics was abandoned in order to perform routine activities, to get back to "normal life", and as symptoms disappeared and the severity of the disease lessened, ${ }^{44,62,69,70}$ participants in the current study did not want to risk side effects caused by consuming antibiotics. Such practices were presented as a care strategy, described by Willis and Chandler ${ }^{27}$ to prevent discomfort since they were experiencing an unknown disease. In previous studies, early cessation of therapy was associated with lay perceptions of recovery from illness, inappropriate knowledge about antibiotics, knowledge and skills on adherence, and concern about AMR..$^{21,71-73}$ In contrast, some participants in the current study felt that completing a treatment course was "unnecessary" as they had recovered from the 
ailment. Consistent with other studies, ${ }^{74-77}$ sharing and following antibiotic prescriptions and medicine regimes were behaviors of some participants in this study. Using the prescriptions of those who had recovered from COVID-19 was widespread, while some participants preferred to follow the antibiotic regimes used by a family member. This is rational for them since it was perceived that the doctors would have prescribed them with similar types of antibiotics and same course. They were able to understand the action efficacy of antibiotics, and to learn curative and safety experience from recovered individuals. These results contrast with another study that found sharing prescriptions saved time and money ${ }^{74}$

This study is not without limitations and the findings should be interpreted in the light of these. Participants do not represent all COVID-19 patients and individuals with symptoms from Bangladesh, therefore, their views may not be generalizable. Although a level of saturation was achieved, this could potentially limit the transferability of the findings. Due to lockdown and travel restrictions, the study used social media posts and personal networks to recruit participants. Therefore, those who sought and consumed antibiotics but were unaware of this study were excluded. These individuals would have added value to the study by sharing their perspectives. However, it is worth exploring antibiotic seeking attitudes and consumption behavior from a user perspective in a complex context following the COREQ guidelines.

\section{Conclusion}

The inductive analysis used in this study highlighted the relational and interlinked relationships between the general public's understanding of antibiotics, and their antibiotic seeking and consumption behaviors with the diverse inscriptions during a health crisis. The categories and sub-categories used in the analysis showed that previous experience of use, perceived vulnerability, distrust of expert advice, and the intrinsic agency of AMR influenced antibiotic seeking behaviors. The analysis also revealed that suboptimal adherence such as modifications to the treatment regimes and adopting treatments prescribed for others were part of a care strategy, while early cessation of treatment was a rational practice to avoid side effects and unknown risks. The explanations reported above demonstrate the need for an emic perspective on everyday practicalities that influence antibiotic practice. The study highly recommends increasing community engagement in AMS interventions to target antibiotic use during the COVID-19 health crisis and beyond. Integrating patients' agency in community engagement activities is potentially critical for an inclusive and participatory AMS. Therefore, AMS messages need to accommodate personal risk management of COVID-19 by a diverse public, particularly in relation to when to seek antimicrobials and to encourage adherence to these once prescribed. As evident elsewhere, a co-designed AMS intervention can result in better outcomes for addressing the socio-cultural and contextual aspects of consumer behavior related to antibiotic seeking and adherence. At the policy level, this study strongly recommends updating relevant guidelines such as the COVID-19 management guideline for home-based patients. Clear instructions and messages should be provided about when to seek antibiotics and how to use these medicines to treat COVID-19, once prescribed.

\section{Acknowledgments}

We would like to thank the research participants who voluntarily gave their valuable time to participate in the study. We also thank Chattogram Veterinary and Animal Science University for giving ethical approval to this study. The authors acknowledge with particular gratitude the anonymous reviewers who offered detailed and helpful comments on the manuscript.

\section{Disclosure}

The authors report no conflicts of interest in this work.

\section{References}

1. World Health Organization. WHO Coronavirus (COVID-19) dashboard. Available from: https://covid19.who.int/. Accessed May $26,2021$.

2. Nieuwlaat R, Mbuagbaw L, Mertz D, et al. Coronavirus disease 2019 and antimicrobial resistance: parallel and interacting health emergencies. Clin Infect Dis. 2021;72(9):1657-1659. doi:10.1093/cid/ciaa773

3. Langford BJ, So M, Raybardhan S, et al. Bacterial co-infection and secondary infection in patients with COVID-19: a living rapid review and meta-analysis. Clin Microbiol Infect. 2020;26(12):1622-1629. doi:10.1016/j.cmi.2020.07.016 
4. Feldman C, Anderson R. The role of co-infections and secondary infections in patients with COVID-19. Pneumonia. 2021;13(1):1-15. doi:10.1186/ s41479-021-00083-w

5. Butler CC, Dorward J, Yu LM, et al. Azithromycin for community treatment of suspected COVID-19 in people at increased risk of an adverse clinical course in the UK (PRINCIPLE): a randomised, controlled, open-label, adaptive platform trial. Lancet. 2021;397(10279):1063-1074. doi:10.1016/S0140-6736(21)00461-X

6. Editorial: Nature Microbiology. Antimicrobial resistance in the age of COVID-19. Nat Microbiol. 2020;5(6):779. doi:10.1038/s41564-020-0739-4.

7. Ansari S, Hays JP, Kemp A, et al. The potential impact of the COVID-19 pandemic on global antimicrobial and biocide resistance: an AMR Insights global perspective. JAC-Antimicrobial Resist. 2021;3(2). doi:10.1093/jacamr/dlab038

8. Hsu J. How covid-19 is accelerating the threat of antimicrobial resistance. BMJ. 2020;369:18-19. doi:10.1136/bmj.m1983

9. Hay SI, Rao PC, Dolecek C, et al. Measuring and mapping the global burden of antimicrobial resistance. BMC Med. 2018;16(1):1-3. doi:10.1186/ s12916-018-1073-z

10. Pierce J, Stevens MP. COVID-19 and antimicrobial stewardship: lessons learned, best practices and future implications. Int J Infect Dis. 2021;113:103-108. doi:10.1016/J.IJID.2021.10.001

11. Aslam A, Gajdács M, Zin CS, et al. Evidence of the practice of self-medication with antibiotics among the lay public in low- and middle-income countries: a scoping review. Antibiot. 2020;9(9):597. doi:10.3390/ANTIBIOTICS9090597

12. Nadimpalli M, Delarocque-Astagneau E, Love DC, et al. Combating global antibiotic resistance: emerging one health concerns in lower- and middle-income countries. Clin Infect Dis. 2018;66(6):963-969. doi:10.1093/CID/CIX879

13. Hassan MM, Kalam MA, Shano S, et al. Assessment of epidemiological determinants of COVID-19 pandemic related to social and economic factors globally. J Risk Financ Manag. 2020;13(9):194. doi:10.3390/jrfm13090194

14. Sawal I, Ahmad S, Tariq W, Tahir MJ, Essar MY, Ahmed A. Unequal distribution of COVID-19 vaccine: a looming crisis. J Med Virol. 2021 ;93 (9):5228-5230. doi:10.1002/JMV.27031

15. Kalam MA Jr., Davis TP, Shano S, et al. Exploring the behavioral determinants of COVID-19 vaccine acceptance among an urban population in Bangladesh: implications for behavior change interventions. PLoS One. 2021;16(8):e0256496. doi:10.1371/JOURNAL.PONE.0256496

16. Huttner BD, Catho G, Pano-Pardo JR, Pulcini C, Schouten J. COVID-19: don't neglect antimicrobial stewardship principles! Clin Microbiol Infect. 2020;26(7):808-810. doi:10.1016/j.cmi.2020.04.024

17. Rawson TM, Ming D, Ahmad R, Moore LSP, Holmes AH. Antimicrobial use, drug-resistant infections and COVID-19. Nat Rev Microbiol. 2020;18 (8):409-410. doi:10.1038/s41579-020-0395-y

18. Rawson TM, Moore LSP, Castro-Sanchez E, et al. COVID-19 and the potential long-term impact on antimicrobial resistance. J Antimicrob Chemother. 2020;75(7):1681-1684. doi:10.1093/JAC/DKAA194

19. Sadio AJ, Gbeasor-Komlanvi FA, Konu RY, et al. Assessment of self-medication practices in the context of the COVID-19 outbreak in Togo. BMC Public Health. 2021;21(1):1-9. doi:10.1186/S12889-020-10145-1

20. Malik M, Tahir MJ, Jabbar R, Ahmed A, Hussain R. Self-medication during Covid-19 pandemic: challenges and opportunities. Drugs Ther Perspect. 2020;36(12):1. doi:10.1007/S40267-020-00785-Z

21. Davey P, Pagliari C, Hayes A. The patient's role in the spread and control of bacterial resistance to antibiotics. Clin Microbiol Infect. 2002;8 (SUPPL. 2):43-68. doi:10.1046/j.1469-0691.8.s.2.6.x

22. Hawkings NJ, Butler CC, Wood F. Antibiotics in the community: a typology of user behaviours. Patient Educ Couns. 2008;73(1):146-152. doi:10.1016/j.pec.2008.05.025

23. Beyene KA, Sheridan J, Aspden T. Prescription medication sharing: a systematic review of the literature. Am J Public Health. 2014;104(4):e15. doi:10.2105/AJPH.2013.301823

24. Okeke IN, Lamikanra A, Edelman R. Socioeconomic and behavioral factors leading to acquired bacterial resistance to antibiotics in developing countries. Emerg Infect Dis. 1999;5(1):18-27. doi:10.3201/eid0501.990103

25. Ahmed I, Rabbi MB, Sultana S. Antibiotic resistance in Bangladesh: a systematic review. Int J Infect Dis. 2019;80:54-61. doi:10.1016/j. ijid.2018.12.017

26. Hoque R, Ahmed SM, Naher N, et al. Tackling antimicrobial resistance in Bangladesh: a scoping review of policy and practice in human, animal and environment sectors. PLoS One. 2020;15(1):1-22. doi:10.1371/journal.pone.0227947

27. Willis LD, Chandler CIR. Anthropology's contribution to AMR control. AMR Control; 2018:84-108. Available from: http://resistancecontrol.info/ wp-content/uploads/2018/05/104-08-chandler.pdf. Accessed January 13, 2022.

28. Jamie K, Sharples G. The social and material life of antimicrobial clay: exploring antimicrobial resistance, medicines' materiality, and medicines optimization. Front Sociol. 2020;5:26. doi:10.3389/fsoc.2020.00026

29. Conrad P. The meaning of medications: another look at compliance. Soc Sci Med. 1985;20(1):29-37. doi:10.1016/0277-9536(85)90308-9

30. Van der Geest S, Whyte SR, Hardon A. The anthropology of pharmaceuticals: a biographical approach. Annu Rev Anthropol. 1996;25(1):153-178. doi:10.1146/annurev.anthro.25.1.153

31. Hardon A, Sanabria E. Fluid drugs: revisiting the anthropology of pharmaceuticals. Annu Rev Anthropol. 2017;46(1):117-132. doi:10.1146/ annurev-anthro-102116-041539

32. Cohen D, McCubbin M, Collin J, Pérodeau G. Medications as social phenomena. Health. 2001;5(4):441-469. doi:10.1177/136345930100500403

33. Rathbone AP, Todd A, Jamie K, Bonam M, Banks L, Husband AK. A systematic review and thematic synthesis of patients' experience of medicines adherence. Res Soc Adm Pharm. 2017;13(3):403-439. doi:10.1016/j.sapharm.2016.06.004

34. Sahoo KC, Tamhankar AJ, Johansson E, Lundborg CS. Community perceptions of infectious diseases, antibiotic use and antibiotic resistance in context of environmental changes: a study in Odisha, India. Health Expect. 2014;17(5):651-663. doi:10.1111/J.1369-7625.2012.00789.X

35. Boiko O, Gulliford MC, Burgess C. Revisiting patient expectations and experiences of antibiotics in an era of antimicrobial resistance: qualitative study. Health Expect. 2020;23(5):1250-1258. doi:10.1111/HEX.13102

36. Will CM. Editorial: beyond behavior? Institutions, interactions and inequalities in the response to antimicrobial resistance. Sociol Heal Illn. $2018 ; 40$ (3):E1-E9. doi:10.1111/1467-9566.12735

37. Wood F. Antimicrobial resistance and medical sociology: research brief. ESRC AMR Res Champion University Bristol; 2016. Available from: https://www.bristol.ac.uk/media-library/sites/social-community-medicine/documents/social-science-and-amr/MedicalSociology\&AMR21092016. pdf. Accessed January 13, 2022. 
38. Charani E, McKee M, Ahmad R, et al. Optimising antimicrobial use in humans - review of current evidence and an interdisciplinary consensus on key priorities for research. Lancet Reg Health - Eur. 2021;7:100161. doi:10.1016/j.lanepe.2021.100161

39. Charani E, Smith I, Skodvin B, et al. Investigating the cultural and contextual determinants of antimicrobial stewardship programmes across low-, middle- and high-income countries—A qualitative study. PLoS One. 2019;14(1):e0209847. doi:10.1371/journal.pone.0209847

40. Davis M. Mind the gap: promoting general public awareness and action on antimicrobial resistance. J Pharm Pract Res. 2020;50(6):463-464. doi:10.1002/jppr.1701

41. King R, Hicks J, Rassi C, et al. A process for developing a sustainable and scalable approach to community engagement: community dialogue approach for addressing the drivers of antibiotic resistance in Bangladesh. BMC Public Health. 2020;20(1):1-13. doi:10.1186/s12889-020-09033-5

42. Cross ELA, Tolfree R, Kipping R. Systematic review of public-targeted communication interventions to improve antibiotic use. $J$ Antimicrob Chemother. 2017;72(4):975-987. doi:10.1093/JAC/DKW520

43. Mitchell J, Cooke P, Baral S, et al. The values and principles underpinning community engagement approaches to tackling antimicrobial resistance (AMR). Glob Health Action. 2020;12(S1). doi:10.1080/16549716.2020.1837484

44. Biswas M, Roy MN, Manik MIN, et al. Self medicated antibiotics in Bangladesh: a cross-sectional health survey conducted in the Rajshahi City. BMC Public Health. 2014;14(1):1-7. doi:10.1186/1471-2458-14-847

45. van der Geest S, Hardon A. Social and cultural efficacies of medicines: complications for antiretroviral therapy. J Ethnobiol Ethnomed. 2006;2 (1):1-5. doi:10.1186/1746-4269-2-48

46. McHorney CA. The contribution of qualitative research to medication adherence; 2016:473-494. doi:10.1007/978-1-4939-2920-7_28.

47. Tong A, Sainsbury P, Craig J. Consolidated criteria for reporting qualitative research (COREQ): a 32-item checklist for interviews and focus groups. Int J Qual Health Care. 2007;19(6):349-357. doi:10.1093/INTQHC/MZM042

48. Islam A, Sayeed MA, Rahman MK, et al. Spatiotemporal patterns and trends of community transmission of the pandemic COVID-19 in South Asia: Bangladesh as a case study. Biosaf Health. 2021;3(1):39-49. doi:10.1016/j.bsheal.2020.09.006

49. Sayeed al-zaman M. Healthcare crisis in Bangladesh during the COVID-19 pandemic. Am J Trop Med Hyg. 2020;103(4):1357-1359. doi:10.4269/ ajtmh.20-0826

50. DGHS. Home care for patients with COVID-19 presenting with mild symptoms; 2020. First Edit. Available from: https://dghs.gov.bd/index.php/bd/ publication/guideline. Accessed January 13, 2021.

51. Akhtar Z, Mah-E-Muneer S, Rashid MM, et al. Antibiotics use and its knowledge in the community: a mobile phone survey during the COVID-19 pandemic in Bangladesh. Antibiot. 2021;10(9):1052. doi:10.3390/ANTIBIOTICS10091052

52. Mah-E-Muneer S, Hassan MZ, Biswas MAAJ, et al. Use of antimicrobials among suspected COVID-19 patients at selected hospitals, Bangladesh: findings from the first wave of COVID-19 pandemic. Antibiot. 2021;10(6):738. doi:10.3390/ANTIBIOTICS10060738

53. Kalam A, Shano S, Khan MA, et al. Understanding the social drivers of antibiotic use during COVID-19 in Bangladesh: implications for reduction of antimicrobial resistance. PLoS One. 2021;16(12):e0261368. doi:10.1371/journal.pone.0261368

54. Rousham EK, Islam MA, Nahar P, et al. Pathways of antibiotic use in Bangladesh: qualitative protocol for the PAUSE study. BMJ Open. 2019;9 (1):28215. doi:10.1136/bmjopen-2018-028215

55. Mohiuddin M, Rashid SF, Shuvro MI, Nahar N, Ahmed SM. Qualitative insights into promotion of pharmaceutical products in Bangladesh: how ethical are the practices? BMC Med Ethics. 2015;16(1):1-9. doi:10.1186/s12910-015-0075-z

56. Laizu J, Parvin R, Sultana N, et al. Prescribing practice of antibiotics for outpatients in Bangladesh: rationality analysis. Am J Pharmacol. 2018;1 (1):1-4.

57. World Health Organization. Clinical management of COVID-19: interim guidance 27 May 2020. Vol. 369; 2020. Available from: https://www.who. int/publications/i/item/clinical-management-of-covid-19. Accessed January 13, 2021.

58. Charmaz K. Constructing Grounded Theory. A Practical Guide Through Qualitative Analysis. London, England: SAGE PublicationsSage UK; 2007.

59. Davis MDM, Stephenson N, Lohm D, Waller E, Flowers P. Beyond resistance: social factors in the general public response to pandemic influenza. BMC Public Health. 2015;15(1):1-9. doi:10.1186/s12889-015-1756-8

60. Lohm D, Davis M, Whittaker A, Flowers P. Role crisis, risk and trust in Australian general public narratives about antibiotic use and antimicrobial resistance. Health Risk Soc. 2020;22(3-4):231-248. doi:10.1080/13698575.2020.1783436

61. Whyte SR, Geest S, Van der, hardon A. Social Lives of Medicines. Cambridge: Cambridge University Press; 2002. Available from:: https://books. google.com.bd/books?hl=en\&id=hLQ79NmzeVsC\&oi=fnd\&pg=PP9\&dq=Social+Lives + of + Medicine\&ots=deYPHq9HU0\&sig=bNi9vCkj8bn5okbb8JIgEBy_rU\&redir_esc $=\mathrm{y} \# \mathrm{v}=$ onepage \&q=SocialLivesofMedicine\&f $\mathrm{f}=$ false. Accessed June 8, 2021.

62. Bagnulo A, Sastre MTM, Kpanake L, Sorum PC, Mullet E. Why patients want to take or refuse to take antibiotics: an inventory of motives. BMC Public Health. 2019;19(1):1-9. doi:10.1186/s12889-019-6834-x

63. Chlabicz S, Rogowska-Szadkowska D, Pytel-Krolczuk B, Marcinowicz L, Milewska AJ, Strumilo J. Patients with respiratory tract infections who do not want antibiotics: direct observational study of primary care in Poland. Fam Pract. 2018;36(2):187-191. doi:10.1093/fampra/cmy058

64. Davis MDM, Lohm DB, Whittaker A, Flowers P. 'Willy nilly' doctors, bad patients, and resistant bodies in general public explanations of antimicrobial resistance. Sociol Heal Illn. 2020:1-15. doi:10.1111/1467-9566.13111

65. Chauhan A, Campbell C. Risk, trust and patients' strategic choices of healthcare practitioners. Sociol Health Illn. 2021;43(1):82-98. doi:10.1111/ $1467-9566.13198$

66. CDC. Antibiotic Prescribing and Use in the U.S; 2017. Available from: https://www.cdc.gov/antibiotic-use/stewardship-report/index.html?CDC AA_refVal=https\%3A\%2F\%2Fwww.cdc.gov\%2Fantibiotic-use \%2Fstewardship-report\%2Frole.html. Accessed July 12, 2021.

67. North J, Tonkin-Crine S, Abel L, Van Hecke O, Wang K, Butler C. Tackling antimicrobial resistance in the community. In:Challenges to Tackling Antimicrobial Resistance Economic and Policy Responses. 2020:45-70. doi:10.1017/9781108864121.004

68. Rodrigues CF. Self-medication with antibiotics in Maputo, Mozambique: practices, rationales and relationships. Palgrave Commun. 2020;6 (1):1-12. doi:10.1057/s41599-019-0385-8

69. Llor C, Hernández S, Bayona C, et al. A study of adherence to antibiotic treatment in ambulatory respiratory infections. Int J Infect Dis. 2013;17(3): e168-e172. doi:10.1016/j.ijid.2012.09.012

70. Fernandez-Lazaro CI, García-González JM, Adams DP, et al. Adherence to treatment and related factors among patients with chronic conditions in primary care: a cross-sectional study. BMC Fam Pract. 2019;20(1):1-12. doi:10.1186/s12875-019-1019-3 
71. Karuniawati H, Hassali MAA, Suryawati S, Ismail WI, Taufik T, Wiladatika A. Public practices towards antibiotics: a qualitative study. Clin Epidemiol Glob Health. 2020;8(4):1277-1281. doi:10.1016/j.cegh.2020.04.027

72. Horvat OJ, Tomas AD, Kusturica MMP, et al. Is the level of knowledge a predictor of rational antibiotic use in Serbia? PLoS One. 2017;12(7): e0180799. doi:10.1371/journal.pone.0180799

73. Erku DA, Mekuria AB, Belachew SA. Inappropriate use of antibiotics among communities of Gondar town, Ethiopia: a threat to the development of antimicrobial resistance. Antimicrob Resist Infect Control. 2017;6(1):1-7. doi:10.1186/s13756-017-0272-2

74. Beyene K, Aspden T, Sheridan J. Prescription medicine sharing: exploring patients' beliefs and experiences. J Pharm Policy Pract. 2016;9(1):1-13. doi:10.1186/s40545-016-0075-5

75. Goldsworthy RC, Schwartz NC, Mayhorn CB. Beyond abuse and exposure: framing the impact of prescription-medication sharing. Am J Public Health. 2008;98(6):1115-1121. doi:10.2105/AJPH.2007.123257

76. Goulding E, Murphy M, Di Blasi Z. Sharing and borrowing prescription medication: a survey of Irish college students. Ir J Med Sci. 2011;180 (3):687-690. doi:10.1007/s11845-011-0698-0

77. Obol JH, Akera P, Atim PO, et al. Prevalence of borrowing and sharing prescription medicines and associated socio-demographic factors: findings from COBERS health centres in northern Uganda. BMC Pharmacol Toxicol. 2018;19(1):1-8. doi:10.1186/s40360-018-0206-5

\section{Publish your work in this journal}

Patient Preference and Adherence is an international, peer-reviewed, open access journal that focusing on the growing importance of patient preference and adherence throughout the therapeutic continuum. Patient satisfaction, acceptability, quality of life, compliance, persistence and their role in developing new therapeutic modalities and compounds to optimize clinical outcomes for existing disease states are major areas of interest for the journal. This journal has been accepted for indexing on PubMed Central. The manuscript management system is completely online and includes a very quick and fair peer-review system, which is all easy to use. Visit http://www.dovepress.com/testimonials.php to read real quotes from published authors.

Submit your manuscript here: https://www.dovepress.com/patient-preference-and-adherence-journal 